\title{
Research of Guidelines for Designing E-study Materials
}

\author{
Kristine Mackare, Anita Jansone \\ Liepaja University, Faculty of Science and Engineering, Address: Kr.Valdemara Str.4, Liepaja, LV-3401, Latvia
}

\begin{abstract}
E-study use is increasing; its main content is information for self-education and it is delivered to the user through modern technologies that provide greater opportunities. In order to reach the user, information must be presented in a comprehensible and easy to remember way. The article focuses on the recommended ways of information presentation in e-studies, so that it would be possible to perceive and memorize information more efficiently, it also focuses on technologies that could help in building and analysing ways of presentation. There are analysed several technology products and presented various examples. The authors offer recommendation Guidelines for development and presentation of e-study materials, their assessment and presentation considering user needs and requirements of research, as well as literature study research, and, also, based on the foundations of visual science. The focus for the development of Guidelines was particularly on the visual function importance in the reading and learning process, as clear and stable text perception primarily is provided by near visual functions. In a structured manner, there are recommendations presented for a user-friendly e-study material design - style, size, spacing, position, colour - which should be applied for easy perception with visual processes, thus helping the learning process and facilitating memorization.

As nowadays there is a growing need for teaching methods and learning environment that is user-oriented, guidance specifics may be different for each of the e-study targeting groups that are divided primarily into three groups: children, adults, and seniors because each group has a different needs, requirements, and visual perception, as well as it is necessary to consider other features of the user which may differ from the standard and affect efficiency of recommendations. This work deals with part of the target group-adults (16-38).
\end{abstract}

Keywords: e-study, e-study environment, technologies, visual perception.

\section{INTRODUCTION}

Technology is all around us and no one can feel comfortable daily without using modern technology. Technologies are developing. And it is not surprising that many of them serve us in delivering visual and textual information. Increasingly, screens are used for learning - in extra-curricular education and selfeducation and in the integration of technology in everyday standardized full-time education and there is a widespread use of e-learning and e-study. Research about reading on the screen has been going on for more than 30 years [1], but still the acquisition of new knowledge about the effects of various parameters is moving slowly [2] and still many things are incomprehensible. Researchers have identified differences in reading from the screen and paper by both complex [1] and simpler tests. [3, 4] Reading digital texts and materials from a computer screen is considered to be much more difficult than reading a printed text. [5] On the computer screen the text is read 25\% slower than from paper. [6] Therefore text formatting parameters which improve reading on the screen are essential. Studies indicate that the text presentation of the parameters to be used are those that are easy and comfortable to be received and natural for people's eyes and human mental development level. [5]
During literature research, it is revealed that many recommendations of the screen texts continue to rely on the printed material developed parameters.

The purpose: establish appropriate recommendations for guidelines about e-material parameter formatting in Latvian

Tasks: 1. literature review paying attention to current recommendations and guidelines, and carrying out analysis of the mentioned parameters; 2 . carry out research on users' habits and preferences; 3 . develop recommendations for guidelines; 4 . carry out research and analyses of applications and browsers based on the elaborated recommendations.

\section{II.MATERIALS AND METHODS}

Literature review

There have been viewed and analysed more than 100 different literature sources. They deal with the recommendations of web development and statistics on the most important parameters which are used in the e-environment, and recommendations and guidelines for e-study courses and e-learning materials, as well as various studies in which researchers have tried to find out the best solution.

A list of most often mentioned formatting parameters has been created. Then there have been written out all mentioned values of parameters and http://dx.doi.org/10.17770/ etr2017vol2.2560 
marked in which sources values have been mentioned and recommended for use. After that analysis was made.

Survey

Research on users' habits and preferences was done by a survey. For this purpose, an e-survey was made. It consisted of several parts. During the first part, there was obtained general information about the respondents - gender, age, education level and occupation. The second part consisted of questions about respondents' technology usage habits and knowledge of e-materials. Third, the main part consisted of questions about formatting options of ematerials where respondents had to provide answers of their own choice. The fourth and the final part was to obtain additional information about respondents' eye health and reading difficulties, if they had any, to be accurately interpreted the responses received. It was a closed-ended questions survey.

For the purpose of this research there was selected an e-questionnaire because it was appropriate not only because it can be quickly carried out, but also because the third part of the questionnaire could be viewed and accurate choices could be made. It had to be done directly on the computer screen. E-survey in this case had a positive effect on the results, as the respondents could act whenever they wanted and in familiar surroundings - at their own screen without additional conditions. Furthermore, it did not have any additional stress that could arise from the presence of the surveyor and changes in the environment or circumstances.

\section{Respondents}

The survey involved 50 respondents aged 16 to 38 $($ Mean $=24.8, \mathrm{SD}=4.6)$ years old. From those 6 were men and 44 - women. They were young people with different levels of education and different current occupation. Respondents were without significant visual defects and without reading difficulties, but 24 participants had vision correction. They joined the survey on a voluntary basis.

\section{Recommendations for guidelines}

There were recommendations for guidelines prototype developed based on literature study of the recommended parameters of different sources and on survey data collected, and on results of previous studies and vison science-based research.

\section{Applications and browsers research}

The research was made about developers' imposed default formatting settings of font type and size in the most popular applications and browsers. The most popular applications were found: Microsoft Office, OpenOffice.org and LibreOffice products, and open access web editors available online: Google, Zoho, Quip products. The most interesting products were word processors, spreadsheets, and presentation programs. After that analysis based on the elaborated recommendations was made. A similar analysis was performed in the most popular browsers - Google
Chrome, Mozilla, Microsoft Edge, Opera, and Safari also.

\section{RESULTS AND DISCUSSION}

Text formatting suggestions in the literature

One of the e-learning design guidelines started with the fact that information must be presented from top to bottom and from right to left. It is recommended to limit the amount of information that is displayed on a single page. $[7,8]$

The text is recommended to be left align [7] to avoid problems with understanding the beginning of the line, and enhance understanding about where the line ends. It isn't recommended to use text justify, as for part of the readers, especially people with dyslexia or other types of reading difficulties, it may disturb the reading process. [9] For splitting a long text, it is recommended to use bullets, numbering, tables, and charts. [7]

The recommended font size and type only of printed educational materials in Latvian national methodological recommendations are mentioned there. [10] They are based on researcher M. A. Tinker's, the University of Minnesota, recommendations that are made from his research in the 30-60's. Furthermore, font size is not the only parameter, that we must pay attention to formatting learning and study e-materials. Textual information presentation and formatting parameters - row length, letter font, font size, line spacing, spacing between letters and combinations of font colour and background colour are very important.

Text line length

The optimal text line length is quite difficult to determine because it depends on the relationship between various formatting factors. [11] Text line length selection is also based on readers' choices and habits. It is important to know about the eye movements, visual angle, and retina usable area per fixation, as well as blinking places. [5]

Saccade is from 1 - 20 symbols, average it is 7-9 symbols. [12] For making fixation movements eyes usually choose 1-6 characters, and then fix 7-12 characters. [13] Blinking is performed to relax the eye muscles, which is making the eyes focus on the reading text, but after blinking to resume reading, it needs again to focus on a reading point. If there is a need in blinking too often and line lengths are too short, then every time the accommodation must be run by again and when it turns out that the muscle all the time is in operation, and it can get tired. Row length needs to be adjusted to the end of the row to coincide with blinking places. It needs to ease the process of reading and reduce eye fatigue. [14] Blinking places will be longer with smaller font sizes, thus creating a positive result for using longer text line. [5]

Although most results of the research about the row lengths show a faster reading at a longer row 
length, [2] however, it is recommended to use short lines of text, [7] because it eases the ability to concentrate to the read-row [15] and readers in research prefer shorter lines. $[15,16]$

By analysing more than 50 literary sources - it was found out that there is no unambiguity about the text line length because in reviewed literature it varies- they should be defined and quantifiable. There are three most popular types - characters per line (CPL), number of words in a row and line length in units' inch or centimetres.

In reviewed literature line length CPL mentioned in 40 sources and its value can be found from 24.7 to 140 characters. It is assumed that the most popular are the ones that are mentioned in more than 10 sources - from 45 to $85 \mathrm{CPL}$. The most common recommended $55 \mathrm{CPL}(\mathrm{n}=23)$, followed by $60 \mathrm{CPL}$ $(\mathrm{n}=19), 75 \mathrm{CPL}(\mathrm{n}=17), 50$ and 65CPL (both $\mathrm{n}=$ 15).

In reviewed literature, row length in words is mentioned in 6 sources and the number found varies from 7 to 20 words. Most commonly recommended 12 words $(\mathrm{n}=4)$ and equally often recommended 13 , 14,15 and $16(n=3)$ word use.

In reviewed literature, line length in units mentioned in 10 sources and their value can be found from 3.3 in or $8.5 \mathrm{~cm}$ to 10.5 in or $26.7 \mathrm{~cm}$ (or more without a maximum value set). They are divided into two groups, which are most frequently recommended: short lines of 3.3 - 4in or 8.5 to $10.2 \mathrm{~cm}$ and long rows 10 in or $25 \mathrm{~cm}$ and longer. Short lines are more contributing to concentrate on the text, $[15,17]$ but long lines - allow quicker review of the text as there is less need to be scrolled, [14, 15] it also shows a higher reading speed [18] and accuracy of the fixation. [19]

Only rarely we find a reference to the reasons why there is such a wide range of these parameters and why the optimal length of the text is quite difficult to determine. That is because it depends on relationship between various formatting factors. [11]

Font or typeface

Font is a specific representation of text characters with its own style that is based on the defined parameters. [20] Each language has its own specific typographic approach. For example, if a font looks typographically good for English, it does not mean that the same font will make such effects in Arabic and Hindi languages. [21] This also applies to the Latvian language because we have specific symbols cedilla and lengthening marks which change the total font X-height. Therefore, the same recommendations for guidelines cannot be applied in all languages. [22]

It should be remembered that on-screen characters are displayed in a way that pixel sizes limit them, and what looked well in printed form may not be as good on the screen. [23] Because of it, many fonts at smaller or much larger size tend to blur. [24]
Analysing more than 35 literary sources it was found out that there is no unambiguity also in text fonts, which should be used for screen reading. A lot is used out of habit and transferred from printed material typographical recommendations.

However, one of the most common and general recommendations is that through the whole e-material there should be maintained a consistent font style. [7] It is recognized that for printed material it is best to use a serif font TimesNewRoman (TNR) and for digital material - a san-serif font Georgia, as both are designed as equivalent. [25]

Sans-serif fonts are mostly mentioned in references (in 30 from 35 sources) as recommended for use. Most mentioned sans-serif fonts are Arial $(n=15)$, Verdana $(n=15)$, and Helvetica $(n=6)$, Trebuchet MS ( $n=3)$, and Calibri $(n=3)$. Cedilla and lengthening marks in the Latvian language are not supported by Helvetica and Trebuchet MS fonts, therefore these are not included in recommendations for e-learning materials in the Latvian language. In just 15 out of 35 sources serif fonts are mentioned as recommended for the use in digital materials. The most commonly referred serif fonts are Georgia $(n=9)$ and Times New Roman $(\mathrm{n}=7)$.

Font size

Size use depends of screen width used, [26] as well as on which browser the page is run or document is viewed, if the parameter default settings work. [27] One of the most common and general recommendations is that through the whole e-material a consistent font size should be maintained. [7] In earlier research more often there were found references to the smaller font size than in latest. [27] It is scientifically proven that a larger font size for reading is more favourable but there are very few studies that have studied the letter sizes, which are above 14 pt. [28] These sizes are also mentioned in different sources differently, basically points (pt), and pixels (px), and for e-materials also in percentage $(\%)$, and EMS, which are used by web page programmers.

For body text in different sources $(n \sim 40)$ it is advised to use a font size of $8 \mathrm{pt}$ and 28pt. However, the most common - from 12pt to 19pt. 12pt $(n=28)$ size as initial for main body are more often mentioned in sources in which comparison with information about it is used, which is currently being used in e-environment and where the target audience is young people. However, more often it leads to the size $14 \mathrm{pt}(\mathrm{n}=34)$, as minimum useable, especially when the target audience is wider and content is intended for the elderly and/or children. Furthermore, studies have been performed with larger font sizes, as a reading distance on screen is larger than the standard reading distance for printed materials. With a larger distance of watching, a smaller font size reaches the retina, so the same size that is used in printed texts, could not be applied. 
For Headlines, of course, it is recommended to use larger font size, but about this there is much less information. In the literature, letter size from $12 \mathrm{pt}$ to $32 \mathrm{pt}$ can be found. Top suggestions are from $14 \mathrm{pt}$ to $26 \mathrm{pt}$ font size to use, but most recommend use $18 \mathrm{pt}$ $(\mathrm{n}=3)$ and $24 \mathrm{pt}(\mathrm{n}=3)$ size.

Line spacing

Multiline readable content must be placed in such a way that the distance between one row symbol lower edge to the next line upper edge should be enough and it makes the text readable. [29] There are also studies which have not shown significant difference in reading speed between the different line spacing sizes. [30] Choosing the size of line spacing the size of the font should be considered. [31]

In the literature $(n=12)$ line spacing is displayed in units and px, and $\mathrm{mm}$, and the percentage of the font size. In units, it varies from 1.15 to 2 , and most commonly it is recommended to use from $1.5(\mathrm{n}=2)$ to $1.6(\mathrm{n}=2)$. As the percentage varies from 90 to $160 \%$, the most commonly recommended to use is at least $120 \%(n=7)$ line spacing.

Colour

One of highlighted prerequisites: through the whole e-material to maintain a common text and graphics colours. [7] It is recommended to use the maximum contrast between the text and the background [32] and use less than 4 colours in one textual material, $[10,21]$ in some cases up to 5-6 colours. [10]

Most often it is recommended to use a dark text on a light background. [33] A black text on a white background is always a good solution, [34] it is visible and legible, [35] as this combination has a high contrast and is called a positive text. [6] A green text on a white background is being considered for use because the human eye has a natural tendency to green colour, as well as the rays are converged on the retina of the eye without the lens adjustment and adaptation that might induce eye fatigue. [36] A grey background increases the saturation of any colour in its foreground. [37] A black text on a grey background is also advisable. [38]

Also, it is recommended to use white letters on a black background because they are high-contrast. [35] They are suitable for higher resolution and awareness raising activities, but for long-term reading, however, they do not fit, like any lightcoloured text on a dark background, as tiring the reader's visual system, [5] in addition, the dark background makes the pupil open more to get more light thus creating a larger eyes focal outflow. [39, 40]

Survey

Samples for survey questions was made based on information from previous literature research. Text samples can be seen on web-page http://www.phdkm.lv/fonti.php .

Font
There was presented a text sample by $14 \mathrm{pt}$ size. Respondents were shown a text in 5 different fonts Times New Roman (TNR), Arial, Verdana, Georgie, Calibri. They had to take look at all 5 examples from which respondents had to choose 3 fonts that seemed the most acceptable to use for on-screen text.

In general, Top3 fonts are Verdana $(\mathrm{n}=35)$ Arial $(n=34)$, Georgia $(n=33)$. There is near also the TNR $(n=28)$ that had the greatest number of choices as the first choice, and it coincided with the Arial $(\mathrm{n}=$ 15). (Fig. 1)

Font size

Each participant had to see the text where each of the previously used 5 fonts were displayed in 4 sizes $10 \mathrm{pt}, 12 \mathrm{pt}, 14 \mathrm{pt}$ un 16pt. Respondents had to choose one size for each font that seemed the most acceptable to use for on-screen text.

In general, most respondents chose $14 \mathrm{pt}$ size $(\mathrm{n}=$ $87)$ and $12 \mathrm{pt}$ size $(\mathrm{n}=81)$, but it was different for each of the fonts. TNR - 14pt $(\mathrm{n}=20)$ and Arial $12 \mathrm{pt}(\mathrm{n}=19)$, Georgia - 14pt $(\mathrm{n}=18)$, Verdana $-12 \mathrm{pt}$ $(\mathrm{n}=20)$ and Calibri - 14pt $(\mathrm{n}=20)$ (Fig. 2$)$

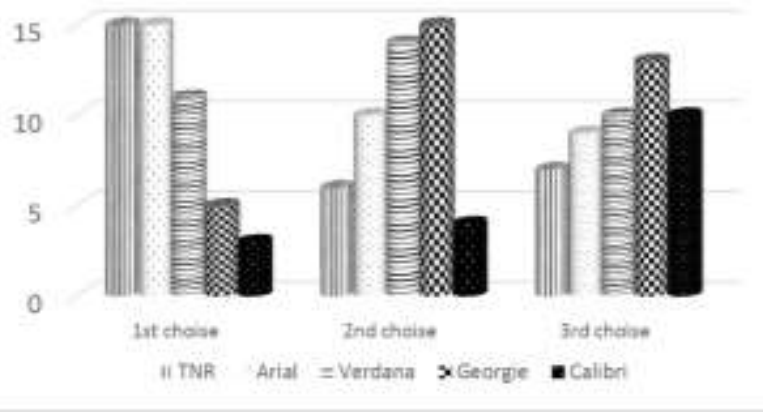

Fig.1 Respondent font choice

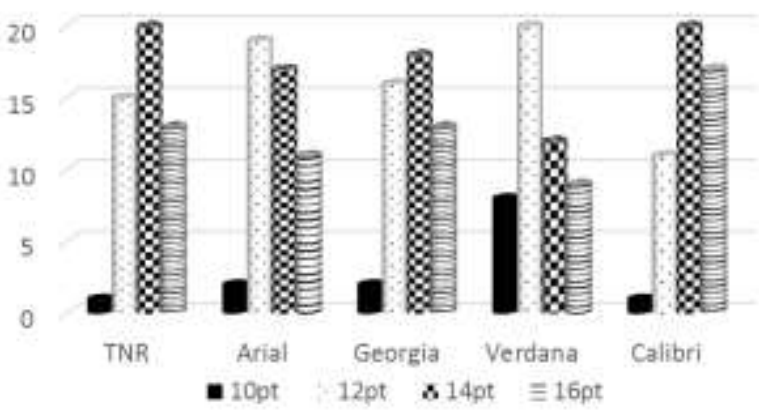

Fig. 2 Respondent font size choice

Line spacing

Each participant had to see the text where each of the previously used 5 fonts were displayed in $14 \mathrm{pt}$ size, but line spacing was changed - 1.0, 1.15, 1.5 and 2.0. Respondents had to choose one line spacing size for each font that seemed the most acceptable to use for on-screen text.

In general, most preferred were $1.15(n=126)$ and $1.5(n=103)$ The size of the space between the lines, but the choice was different for each of the fonts. TNR - $1.15(\mathrm{n}=31)$ Arial - $1.15(\mathrm{n}=26)$, Georgia - 
Environment. Technology. Resources, Rezekne, Latvia Proceedings of the $11^{\text {th }}$ International Scientific and Practical Conference. Volume II, 90-96

$1.5(\mathrm{n}=28)$, Verdana $-1.5(\mathrm{n}=20)$ and Calibri -1.15 $(\mathrm{n}=29)$. (Fig. 3)

Colour

Each participant had to see the text written with TNR 14pt font size, each of the options changed text font colour and background colour combination. It was created in 7 different versions: black text on a white background, white - on black, grey - on white, blue on white, green - on white, green - on blue and yellow - on a red background. Respondents had to choose 3 colour combination that seemed the most acceptable to use for on-screen text.

In general, Top3 colour combination is black and white $(\mathrm{n}=40)$ grey to white and green $(\mathrm{n}=32)$ and white $(n=21) .9$ respondents decided that there are only two options, which should be applied when displaying text on the screen. (Fig. 4)

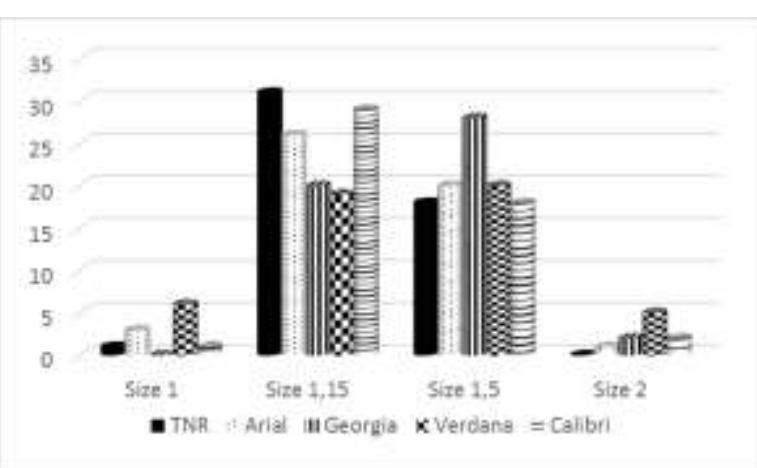

Fig. 3 Respondents line spacing choice

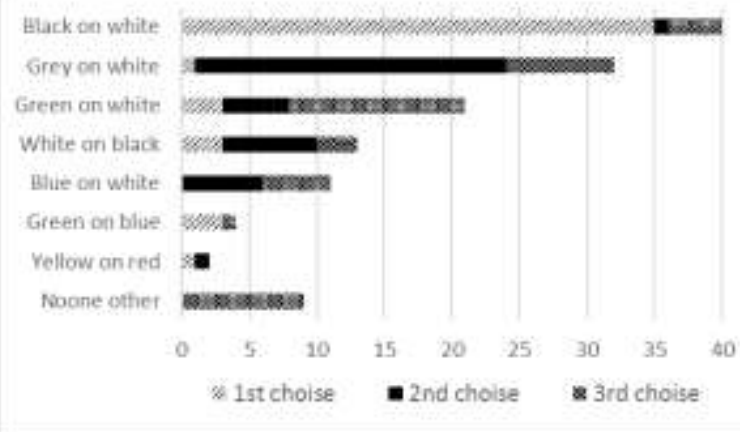

Fig. 4 Respondent colour choice

Recommendations for guidelines

These recommendations have been developed for e-learning materials and studying for one target group - young people - without reading difficulties and without any significant vision problems. Recommendations are shown in table 1 .

Table 1 Recommendations

\begin{tabular}{|l|l|}
\hline \multicolumn{1}{|c|}{$\begin{array}{l}\text { FORMATTING } \\
\text { PARAMETERS }\end{array}$} & \multicolumn{1}{c|}{ RECOMMENDATIONS } \\
\hline Text layout & Left align \\
\hline Line length & $55-75 \mathrm{CPL}$ \\
& $\sim 15 \mathrm{~cm}$ \\
\hline Font & $\begin{array}{l}\text { Body text: } \\
\text { Arial, Verdana, Georgia un TNR } \\
\end{array}$ \\
& Heading: Can use also other fonts \\
\hline
\end{tabular}

\begin{tabular}{|l|l|}
\hline Size & $\begin{array}{l}\text { Body text }- \text { min. 14pt } \\
\text { Headings }- \text { min. 18pt }\end{array}$ \\
\hline Line spacing & 1,15 or 1,5 \\
\hline Colour & $\begin{array}{l}\text { Black text on white background } \\
\text { Grey text on white background } \\
\text { Green text on white background }\end{array}$ \\
\hline
\end{tabular}

Applications and browsers research

There is no single standard to be applied by developers. There is seen a use of different fonts and sizes for both body text and headings in applications and browsers. It is shown in table 2 un table 3.

\begin{tabular}{|c|c|c|}
\hline & \multicolumn{2}{|c|}{ WORD PROCESSOR } \\
\hline APPLICATIONS & BODY TEXT & HEADING \\
\hline Microsoft Office & Calibri 11pt & TNR 24pt \\
\hline LibreOffice & $\begin{array}{l}\text { Liberation Serif } \\
12 \mathrm{pt}\end{array}$ & $\begin{array}{l}\text { Liberation Sans } \\
18,2 \mathrm{pt}\end{array}$ \\
\hline OpenOffice.org & Calibri 12pt & Arial $16,1 \mathrm{pt}$ \\
\hline \multicolumn{3}{|l|}{ Web editors } \\
\hline Google & Arial $11 \mathrm{pt}$ & Arial 20pt \\
\hline Zoho & Arial 11pt & Arial Black 18pt \\
\hline \multirow[t]{2}{*}{ Quip } & Calibri 12pt & Calibri 24pt \\
\hline & SPREADSHEETS & \\
\hline Applications & Body Text & \\
\hline Microsoft Office & Calibri 11pt & \\
\hline LibreOffice & $\begin{array}{l}\text { Liberation Sans } \\
10 \mathrm{pt}\end{array}$ & \\
\hline OpenOffice.org & Arial 10pt & \\
\hline \multicolumn{2}{|l|}{ Web editors } & \\
\hline Google & Arial 10pt & \\
\hline \multirow[t]{2}{*}{ Zoho } & Arial 10 & \\
\hline & \multicolumn{2}{|c|}{ PRESENTATIONS } \\
\hline Applications & Body Text & Heading \\
\hline Microsoft Office & Calibri 28pt & Calibri Light $60 \mathrm{pt}$ \\
\hline LibreOffice & $\begin{array}{l}\text { Liberation Sans } \\
32 \mathrm{pt}\end{array}$ & $\begin{array}{l}\text { Liberation Sans } \\
44 \mathrm{pt}\end{array}$ \\
\hline OpenOffice.org & Arial 32 & Arial 44pt \\
\hline Web editors & & \\
\hline Google & Arial 18pt & Arial 52pt \\
\hline Zoho & $\begin{array}{l}\text { Roboto Normal } \\
18 \mathrm{pt}\end{array}$ & Roboto Thin 51pt \\
\hline
\end{tabular}

Table 3 Browsers default formatting settings

\begin{tabular}{|l|l|l|l|}
\cline { 2 - 4 } \multicolumn{1}{c|}{} & \multicolumn{3}{|c|}{ DEFAULT FORMATTING SETTINGS } \\
\hline BROWSERS & Standard font & Serif font & $\begin{array}{l}\text { Sans-serif } \\
\text { font }\end{array}$ \\
\hline Google Chrome & TNR 12pt & TNR 12pt & Arial 12pt \\
\hline Mozilla & TNR 16pt & TNR 16pt & Arial 16pt \\
\hline Microsoft Edge & Segoe UI 12pt & & \\
\hline Opera & TNR 12pt & TNR 12pt & Arial 12pt \\
\hline Safari & TNR 16pt & & \\
\hline
\end{tabular}




\section{CONCLUSION}

Analysing more than 100 literary sources publications, recommendations for e-learning materials and web page creation - it was found that there is no unambiguity about all formatting parameters.

Most respondents chose a larger font size, even young people. This shows that for e-materials there cannot be used standard printed material recommendations directly.

Based on all information, research and survey, recommendations for adult people were made.

These recommendations must be checked experimentally in the target group by combined complexes in the context of e-material to confirm their effectiveness. Recommendations are supplemented by additional parameters. Also, there is a need to develop complementary recommendations, depending on the individual in addition to human factors, which may significantly affect reading and text perception - depending on their age, visual status, reading difficulties, and so on - because each person has different needs and opportunities.

\section{REFERENCES}

[1] Rayner, K. Eye movements in reading and information processing: 20 years of research. Psychological Bulletin. 1998. Vol.124 p.372-422

[2] Dyson, C.M. How physical text layout affects reading from screen, Behavior \& Information technology, NovemberDecember 2004, Vol.23 No6, 377-393

[3] Pozṇaka K. Redzes atmiṇas tests latviešu valodā: bakalaura darbs. LU Fizikas un matemātikas fakultāte. Rīga: Latvijas Universitāte, 2013

[4] Pozṇaka K. Lasiššnas atminnas novērtēšana ar tekstu uz monitora un drukātu tekstu: magistra darbs. LU Fizikas un matemātikas fakultāte. Rīga: Latvijas Universitāte, 2015

[5] Muzammil Khan, Khushdil; Comprehensive Study on the Basis of Eye Blink, Suggesting Length of Text Line, Considering Typographical Variables the Way How to Improve Reading from Computer Screen; Advances in Internet of Things Vol.3 No.1(2013)

[6] Nielsen, J. "Designing Web Usability: The Practice of Simplicity," New Riders Publishing, Indianapolis, 2000, p. 420.

[7] Washington State Department of State, eLearning Design Guid, WSDOT, 2013

[8] Lynch, J.P., Horton, S. Web Style Guide 4th edition, 2016

[9] Dyslexie font, Tex loyout, https://www.dyslexiefont.com/en/backgroundinformation/text-layout-advice/ (Piekḷuve: 12.03.2017.)

[10] Autoru grupa, Valsts izglîtīibas standartiem atbilstošas mācību literatūras satura izstrāde uz izvêrtěšana, Metodiskie materiāli,

[11] Olyslager, P. The Optimal Text Layout is More Than Line Length, 2012 https://www.paulolyslager.com/optimal-textlayout-line-length/ (Piekḷuve: 12.02.2017.)

[12] Rayner, K., Foorman, B., Perfetti, C., Pesetsky, D., Seidenberg, M. How Psychological Science Informs the Teaching of Reading. Psychological Science in the Public Interest 2001. N 2 p.31-74.

[13] Rayner, K. The perceptual span and peripheral cues in reading. Cognitive Psychology 1975. Vol.7 p.65-81

[14] Raza, M. Length of Text Line on the Bases of Eye Blink to Reduce Maximum Focus Losses. International Journal of Computer Applications 2012. N 8 p.15-21

[15] Bernard, L.M., Fernandez, M., Hull, S. \& Chaparro, B.S., The effects of line length on children and adults' perceived and actual online reading performance, Proceeding of the human factors and ergonomics society $47^{\text {th }}$ annual meeting 2003

[16] Azuma, M., Ikeda, T., Minomoto, T., Osaka, M., Osaka, N. High working memory performers have efficient eye movement control systems under Reading Span Test Journal of Eye Movement Research 2012. N 5 p.1-10

[17] Bernard, M., Fernandes, M., Hull, S. The Effects of Line Length on Children and Adults' Online Reading Performance. Usability News 2002. Vol.4

[18] Rayner, K., Slattery, T. J., Bélanger, N.N. Eye movements, the perceptual span, and reading speed. Psychon Bull Rev. 2010 Vol.17 p. 834-839

[19] Dyson, M. C., Kipping, G. J. The elects of line length and method of movement on patterns of reading from screen. Visible language 1998. Vol.32 p.150-181

[20] Definition http://whatis.techtarget.com/definition/font (Piekḷuve 22.02.2017.)

[21] Clarke, A. 12 Typography Guidelines for Good Website Usability, 2012 http://usabilitygeek.com/12-typographyguidelines-for-good-website-usability/ (Piekḷuve: 3.02.2017.)

[22] Ganayim, D., Ibrahim, R., How Do Typographical Factors Affect Reading Text and Comprehension Performance in Arabic?; Human Factor Vol. 55, No. 2, April 2013, pp. 323332

[23] Reynolds, Dan. How To Choose The Right Face For A Beautiful Body, Smashing. Retrieved 13 September 2015

[24] Frere-Jones, Tobias. "MicroPlus". Frere-Jones Type. Retrieved 1 December 2015. https://frerejones.com/blog/introducing-microplus (Piekḷuve: 22.02.2017.)

[25] Miellet, S, O'Donnell, P.J, Sereno, S.C. Parafoveal magnification: Visual acuity does not modulate the perceptual span in reading. Psychological Science. 2009. Vol.20 p.721728

[26] Constantin, J., Typographic Design Patterns And Current Practices,

2013 https://www.smashingmagazine.com/2013/05/typographicdesign-patterns-practices-case-study-2013/ (Piekḷve: 12.03.2017.)

[27] Marc Schenker, Why Online Fonts Need to Be Bigger Than You Expect for Awesome UX, 2016, https://www.paulolyslager.com/why-online-fonts-biggerawesome-ux/ (Piekluve: 12.02.2017.)

[28] Martin, Optimal Font Size for Web Pages (CHI 2016), http://pielot.org/2016/01/optimal-font-size-for-web-pages/ (Piekluve: 13.02.2017.)

[29] What's the Difference Between Leading, Kerning and Tracking? $2016 \mathrm{https://creativemarket.com/blog} /$ whats-thedifference-between-leading-kerning-and-tracking (Piekluve: 3.02.2017.)

[30] Soleimani, H., Mohammadi, E. The Effect of Text Typographical Features on Legibility, Comprehension, and Retrieval of EFL Learners, English Language Teaching; Vol. 5, No. $8 ; 2012$

[31] Idler, S., 8 Guidelines For Better Readability On The Web, 2012, http://blog.usabilla.com/8-guidelines-for-betterreadability-on-the-web/ (Piekḷuve: 12.03.2017.)

[32] Nielsen, J., Readability Guidelines for Websites, 2002, https://www.nngroup.com/articles/let-users-control-font-size/ (Piekḷuve: 12.03.2017.)

[33] Nix, T., Skyrocketing Your Web Content's Readability, http://nectafy.com/readability-guidelines/ $\quad$ (Piekluve: 12.03.2017.)

[34] Pappas, C., Typography In eLearning: 5 Key Tips For eLearning Professionals, 2015 https://elearningindustry.com/typography-in-elearning-5-keytips-for-elearning-professionals (Piekluve: 12.03.2017.)

[35] Hall, R.H., Hanna, P. The impact of web page textbackground colour combinations on readability, retention, aesthetics and behavioural intention, Behaviour \& Information technology, May-June 2004, Vol.23, No3, 183195

[36] Rasheed, H., Eye Specialist, Saidu Medical College, Saidu 
Environment. Technology. Resources, Rezekne, Latvia Proceedings of the $11^{\text {th }}$ International Scientific and Practical Conference. Volume II, 90-96

[37] Richardson, R.T., Drexler, L.T., Delparte, M.D., Color and Contrast in E-Learning Design: A Review of the Literature and Recommendations for Instructional Designers and Web Developers, MERLOT Journal of Online Learning and Teaching, Vol. 10, No. 4, December 2014

[38] Hill, A., Scharff, L. V. Readability of screen displays with various foreground/ background color combinations, font styles, and font types," Proceedings of the Eleventh National Conference on Undergraduate Research, II, 1997, 742-746

[39] Harrison, J., Sensory Perception and Interaction Research Group, University of British Columbia

[40] Scharff, L. V., Ahumada, A. J. (2005). Why is light text harder to read than dark text? [Abstract]. Journal of Vision, $5(8): 812,812 \mathrm{a}$ 